\title{
The impact of delayed source control and antimicrobial therapy in 196 patients with cholecystitis-associated septic shock: a cohort analysis
}

\author{
Constantine J. Karvellas, MD \\ Victor Dong, MD \\ Juan G. Abraldes, MD, PhD \\ Erica L.W. Lester, MD, MSc \\ Anand Kumar, MD
}

Accepted Oct. 1, 2018

\author{
Correspondence to: \\ C.J. Karvellas \\ Associate Professor of Medicine \\ Department of Critical Care Medicine \\ Division of Gastroenterology (Liver Unit) \\ University of Alberta \\ Edmonton AB T6G 2X8 \\ dean.karvellas@ualberta.ca
}

DOI: $10.1503 /$ cjs.009418
Background: Cholecystitis-associated septic shock carries a significant mortality. Our aim was to determine whether timing of source control affects survival in cholecystitis patients with septic shock.

Methods: We conducted a nested cohort study of all patients with cholecystitisassociated septic shock from an international, multicentre database (1996-2015). Multivariable logistic regression was performed to determine associations between clinical factors and in-hospital mortality. The results were used to inform a classification and regression tree (CART) analysis that modelled the association between disease severity (APACHE II), time to source control and survival.

Results: Among 196 patients with cholecystitis-associated septic shock, overall mortality was $37 \%$. Compared with nonsurvivors $(n=72)$, survivors $(n=124)$ had lower mean admission APACHE II scores (21 v. 27, $p<0.001)$ and lower median admission serum lactate $(2.4$ v. $6.8 \mu \mathrm{mol} / \mathrm{L}, p<0.001)$. Survivors were more likely to receive appropriate antimicrobial therapy earlier (median 2.8 v. $6.1 \mathrm{~h}$ from shock, $p=0.012$ ). Survivors were also more likely to undergo successful source control earlier (median 9.8 v. $24.7 \mathrm{~h}$ from shock, $p<0.001$ ). Adjusting for covariates, APACHE II (odds ratio [OR] 1.13, 95\% confidence interval [CI] 1.06-1.21 per increment) and delayed source control > 16 h (OR 4.45, 95\% CI 1.88-10.70) were independently associated with increased mortality (all $p<0.001$ ). The CART analysis showed that patients with APACHE II scores of 15-26 benefitted most from source control within $16 \mathrm{~h}(p<0.0001)$.

Conclusion: In patients with cholecystitis-associated septic shock, admission APACHE II score and delay in source control (cholecystectomy or percutaneous cholecystostomy drainage) significantly affected hospital outcomes.

Contexte : Le choc septique associé à une cholécystite s'accompagne d'une mortalité significative. Notre but était de déterminer si le moment du contrôle de la source affecte la survie chez les patients atteints de cholécystite qui se trouvent en choc septique.

Méthodes : Nous avons procédé à une étude de cohorte nichée regroupant tous les patients ayant présenté un choc septique associé à une cholécystite à partir d'une base de données multicentrique internationale (1996-2015). La régression logistique multivariée a été utilisée pour déterminer les liens entre les facteurs cliniques et la mortalité perhospitalière. Les résultats ont été utilisés pour éclairer une analyse par arbre de classification (CART) qui modélisait le lien entre la gravité de la maladie (APACHE II), le temps nécessaire au contrôle de la source et la survie.

Résultats : Parmi 196 patients souffrant d'un choc septique associé à une cholécystite, la mortalité globale a été de $37 \%$. Comparativement aux patients décédés $(n=72)$, les survivants $(n=124)$ présentaient à l'admission des scores APACHE II moyens plus bas $(21$ c. $27, p<0,001)$ et un taux de lactate sérique médian plus bas $(2,4$ c. $6,8 \mu \mathrm{mol} / \mathrm{L}, p<0,001)$. Les survivants étaient plus susceptibles de recevoir une antibiothérapie adéquate plus hâtive (médiane 2,8 c. $6,1 \mathrm{~h}$ suivant le choc, $p=$ 0,012). Les survivants étaient aussi plus susceptibles de bénéficier plus hâtivement d'un contrôle réussi de la source (médiane 9,8 c. 24,7 h suivant le choc, $p<0,001$ ). L'ajustement pour tenir compte des covariables du score APACHE II (rapport des cotes $[\mathrm{RC}] 1,13$, intervalle de confiance [IC] de $95 \%$ 1,06-1,21 par palier) et le retard du contrôle de la source > 16 h (RC 4,45, IC de $95 \%$ 1,88-10,70) ont été associés indépendamment à une mortalité plus élevée (tous deux $p<0,001$ ). 
L'analyse CART a révélé que les patients ayant des scores APACHE II de 15-26 ont le plus bénéficié d'un contrôle de la source dans les $16 \mathrm{~h}(p<0,0001)$.

Conclusion : Chez les patients présentant un choc septique associé à une cholécystite, le score APACHE II à l'admission et le retard de contrôle de la source (cholécystectomie ou drainage par cholécystotomie percutanée) ont significativement influé sur les résultats hospitaliers.

cute cholecystitis is characterized by inflammation of the gallbladder and is diagnosed when there are local signs of inflammation (positive Murphy sign/ right upper quadrant pain), signs of systemic inflammation (fever), and when imaging is consistent (thickened gallbladder wall on ultrasound and/or pericholecystic fluid). ${ }^{1}$ If left untreated, acute cholecystitis will likely lead to serious complications, including perforation, septic shock, multiorgan failure and death. ${ }^{2,3}$ Cholecystectomy is currently the gold standard therapy, with drainage via percutaneous cholecystostomy as an alternative option in patients with high surgical risks. ${ }^{4}$

Previous studies of hospitalized patients with acute cholecystitis have shown that delayed cholecystectomy of more than 24 to $48 \mathrm{~h}$ is associated with increased morbidity, postoperative complications and longer hospital stay. 5,6 For patients not fit for surgery, delayed percutaneous cholecystostomy drainage of more than 24 hours is associated with increased morbidity and length of hospital stay (LOS). ${ }^{7}$ However there remains uncertainty regarding optimal timing of cholecystectomy or cholecystostomy drainage in hospitalized patients with acute cholecystitis, especially in the critically ill population. This situation presents therapeutic challenges, as not all hospitals have access to interventional radiology and acute care surgery.

Patients with acute cholecystitis with concomitant bacteremia and septic shock represent a potentially higher-risk population with even greater therapeutic challenges. Acute cholecystitis with bacteremia is associated with worse outcomes, specifically acute kidney injury, septic shock and increased mortality. ${ }^{8}$ In patients with septic shock, early administration of antimicrobial therapy has been shown to significantly reduce mortality. ${ }^{9}$ However, there remains a dearth of evidence regarding timing of source control in patients with septic shock with acute cholecystitis.

In this study, we evaluated important clinical factors associated with mortality in critically ill patients with septic shock due to acute cholecystitis. Specific predefined practice-related factors that were examined included time to successful source control, time to appropriate antimicrobial therapy and severity of illness.

\section{Methods}

We conducted a nested cohort study. Patients with cholecystitis and septic shock were drawn from the larger retrospective cohort population from the Cooperative Antimicrobial Therapy of Septic Shock [CATSS] database of cases with septic shock collected from 28 medical centres in Canada, the United States and Saudi Arabia for discrete continuous periods between 1996 and 2015. ${ }^{10}$ The details of the database characteristics are available elsewhere. ${ }^{11}$ We obtained ethical approval from the institutional review boards of all institutions participating in the CATSS registry, including the University of Manitoba Health Research Ethics Board. As this was a retrospective study, waived consent was obtained from each participating site. This study was written according to the STROBE guideline for reporting retrospective studies ${ }^{12}$ and was compliant with the Declaration of Helsinki (2013) ethical principles for medical research involving humans.

\section{Study design: patients and setting}

Data were extracted for all $(n=196)$ adult patients with acute cholecystitis-associated septic shock in the CATSS database. Diagnosis of acute cholecystitis was based on the presence of local signs of inflammation (positive Murphy sign and/or right upper quadrant pain) along with signs of systemic inflammation (fever) and when imaging was consistent with acute cholecystitis. ${ }^{1}$ These published criteria were consistent with the Tokyo guideline. ${ }^{1}$ All infections met Centers for Disease Control and Prevention (CDC) criteria for intra-abdominal infection. ${ }^{13}$

\section{Exposures and outcomes}

Baseline patient characteristics, including demographics and comorbid conditions, were obtained at enrolment into the registry. The following data were obtained on day 1 (within $24 \mathrm{~h}$ ) of shock development: bicarbonate level, serum lactate, bilirubin, creatinine, platelet count, international normalized ratio (INR), white blood cell (WBC) count, number of organ failures and Acute Physiology And Chronic Health Evaluation (APACHE) II score. ${ }^{14}$ The primary outcome of this study was in-hospital mortality. Secondary outcomes included hospital and ICU lengths of stay. Timing of therapy (antibiotics, source control with cholecystectomy or cholecystostomy drainage) was defined as time of development of shock (hypotension with a mean arterial pressure $<65 \mathrm{~mm} \mathrm{Hg}$ and need for vasopressor support) to the time of receipt of therapy. Successful source control was defined as open if the patient underwent cholecystectomy or a drainage via cholecystostomy in the operating theatre. Successful closed source control included percutaneous cholecystostomy drainage. 


\section{Operational definitions}

Septic shock was defined using the 1992 American College of Chest Physicians/Society of Critical Care Medicine (ACCP/SCCM) guideline..$^{15}$ As per that definition, patients were required to have documented or suspected infection, persistent hypotension requiring vasopressors, and 2 of the following 4 elements: a heart rate of $>90$ beats/min, a respiratory rate of $>20$ breaths/min or arterial partial pressure of carbon dioxide $\left(\mathrm{PaCO}_{2}\right)$ of $<32 \mathrm{~mm} \mathrm{Hg}$, a core temperature of $<36^{\circ} \mathrm{C}$ or $>38^{\circ} \mathrm{C}$, and a WBC count of $<4000 / \mathrm{mL}$ or $>12000 / \mathrm{mL}$ or bands $>10 \%$. An episode of hypotension was considered to represent the initial onset of septic shock when hypotension persisted from onset despite fluid $(2 \mathrm{~L}$ of saline or equivalent) administration (persistent hypotension) or hypotension was only transiently improved (hypotension resolution for $<1 \mathrm{~h}$ ) with fluid resuscitation (recurrent hypotension). ${ }^{9}$ Predetermined rules were used to define documented and suspected infections and to assign significance to clinical isolates as previously described. ${ }^{11}$ Nosocomial infection-related septic shock was defined as septic shock caused by any infection developing more than $48 \mathrm{~h}$ after hospital admission.

Predetermined rules were used to assess the appropriateness and delays of initial empiric antimicrobial therapy. ${ }^{9,11,16}$ For culture-positive septic shock, initial antimicrobial therapy was considered appropriate if an antimicrobial with in vitro bactericidal activity appropriate for the isolated pathogen or pathogens was the first new antimicrobial agent given after the onset of recurrent or persistent hypotension or was initiated within 6 hours of the administration of the first new antimicrobial agent (i.e., part of a new group of antibiotics all initiated within $6 \mathrm{~h}$ of each other). Otherwise, the initial therapy was considered inappropriate. ${ }^{11}$ For culture-negative septic shock, initial therapy was considered appropriate when an antimicrobial agent consistent with broadly accepted norms for empiric management of the typical pathogens for the clinical syndrome was the first new antimicrobial agent given after the onset of recurrent or persistent hypotension or was initiated within $6 \mathrm{~h}$ of administration of the first new antimicrobial agent (i.e., part of a new group of antibiotics all initiated within $6 \mathrm{~h}$ of each other). ${ }^{11}$ At each participating institution, infectious disease physicians/microbiologists were consulted to account for the local community and nosocomial flora when considering appropriateness of empiric therapy during the period covered by data collection. Otherwise, appropriate empiric therapy of culture-negative infections leading to septic shock was based on the recommendations listed in the "Clinical Approach to Initial Choice of Antimicrobial Therapy" from the Sanford Guide to Antimicrobial Therapy (most recently available edition at the time of the case).

\section{Statistical analysis}

Statistical analysis was performed using SPSS version 20 and R (www.r-project.org) software. Continuous variables are reported as means with standard deviations (SD) and medians with interquartile ranges (IQR) following testing for normality. Measures of central tendency for continuous variables were compared using the Student $t$ test (normal distribution) and Wilcoxon rank sum test (nonparametric variables) following normality testing. Categorical variables are reported as numbers and percentages and were analyzed using the $\chi^{2}$ test and Fisher exact test when there were fewer than 5 cases. We considered results to be significant at $p<0.05$ or having a trend toward significance at $p<0.15$. To study the association between clinically relevant factors (severity of illness, time delay to source control and effective antimicrobial therapy) and in-hospital mortality (dependent variable), multivariable logistic regression analyses were performed. Covariates were included based on their significance in the univariable regression analysis $(p<0.05)$, and demographic/physiologic plausibility. Collinear variables were excluded. Results were reported as adjusted odds ratios (OR) with $95 \%$ confidence intervals (CI). Model performance was assessed using the c-statistic (area under the receiver operator curve; AUROC) and Hosmer-Lemeshow goodness of fit test. Unadjusted and adjusted risk plots were constructed with the visreg and rms $\mathrm{R}$ packages. To better model the association between APACHE II score, time to source control and hospital survival, we conducted classification and regression tree (CART) analysis using the CHAID $\left(\chi^{2}\right.$ automatic interaction detection) algorithm. ${ }^{17}$

\section{Results}

\section{Participants and descriptive data}

In total, 196 patients with acute cholecystitis and septic shock (mean age $69.9 \pm 14.4 \mathrm{yr}, 70 \%$ men) were included in this analysis (Table 1). On presentation with septic shock, the mean APACHE II score was $23 \pm 8$. Patients had a cumulative mean of $3.7 \pm 1.5,4.3 \pm 1.7$ and $4.4 \pm$ 1.7 organ failures on days 1,3 and 5 of the study, respectively. During post-shock ICU/hospital stay, 17 (8.7\%) patients were placed on renal replacement therapy, 154 (79\%) patients received mechanical ventilation, and $100 \%$ required vasopressor support (as per definition). The peak mean serum lactate level (within $24 \mathrm{~h}$ of shock) was $5.1 \pm 4.9 \mathrm{mmol} / \mathrm{L}$. For the overall cohort, the median bilirubin was 31 (IQR 16-59) $\mathrm{mmol} / \mathrm{L}$, creatinine was 163 (IQR 97-285) $\mathrm{mmol} / \mathrm{L}$ and INR was 1.6 (IQR 1.4-2.0) (first $24 \mathrm{~h}$ post-shock maximum). The median overall length of ICU stay was 6 (IQR 3-10) days. 
The median overall LOS was 15 (IQR 8-25) days; the median LOS was 17 (IQR 11-31) days for survivors and the median survival duration (i.e., LOS) was 7 (IQR $3-18)$ days for nonsurvivors $(p<0.001)$. In total 139 patients $(71 \%)$ survived to ICU discharge while 124 patients $(63 \%)$ survived to hospital discharge (primary end point).

\section{Microbiology descriptive data}

Pathogen and diagnostic information is shown in Table 2. Of 196 patients, $122(62 \%)$ were culture-positive (biliary/ intra-abdominal, bloodstream or both), while 74 (38\%) were culture-negative. Seventy-three patients (37\%) had a pathogen-isolated bloodstream culture. One hundred

\section{Table 1. Baseline characteristics of 196 patients with cholecystitis and septic shock}

\begin{tabular}{|c|c|c|c|}
\hline Characteristic & $\begin{array}{l}\text { No. patients with } \\
\text { available data }\end{array}$ & Mean $\pm \mathrm{SD}$ or median (IQR) & No. (\%) \\
\hline Age, yr & 196 & $69.9 \pm 14.4$ & \\
\hline Male sex & 196 & - & $138(70)$ \\
\hline Body mass index & 82 & $29.0 \pm 7.2$ & - \\
\hline APACHE II score & 182 & $23 \pm 8$ & - \\
\hline \multicolumn{4}{|l|}{ Organ failure* } \\
\hline Day 1 & 196 & $3.7 \pm 1.5$ & - \\
\hline Day 3 & 196 & $4.3 \pm 1.7$ & - \\
\hline Day 5 & 196 & $4.4 \pm 1.7$ & - \\
\hline Renal replacement therapy (any day) & 196 & - & $17(8.7)$ \\
\hline Vasopressor use (any day) & 196 & - & $196(100)$ \\
\hline Mechanical ventilation (other than in operating theatre) & 196 & - & $154(79)$ \\
\hline \multicolumn{4}{|l|}{ Biochemistry (within first $24 \mathrm{~h}$ of shock) } \\
\hline Sodium, mmol/L & 134 & $139 \pm 6$ & - \\
\hline Bicarbonate, mmol/L & 129 & $20 \pm 5$ & - \\
\hline Lactate, mmol/L & 124 & $5.1 \pm 4.9$ & - \\
\hline Bilirubin, $\mu \mathrm{mol} / \mathrm{L}$ & 183 & $31(15-59)$ & - \\
\hline Creatinine, $\mu \mathrm{mol} / \mathrm{L}$ & 191 & $163(97-285)$ & - \\
\hline Albumin, $\mu \mathrm{mol} / \mathrm{L}$ & 18 & $28 \pm 9$ & - \\
\hline Platelet count, $\times 10^{9} / \mathrm{L}$ & 191 & $111(57-162)$ & - \\
\hline INR & 185 & $1.6(1.4-2.0)$ & - \\
\hline White blood cell count, $\times 10^{6} / \mu \mathrm{L}$ & 182 & $15.8(10.7-22.9)$ & - \\
\hline \multicolumn{4}{|l|}{ Therapies } \\
\hline APC & 196 & - & $7(3.5)$ \\
\hline Corticosteroids (hydrocortisone) & 196 & - & $43(22)$ \\
\hline \multicolumn{4}{|l|}{ Appropriate antimicrobials, no. patients who survived $t$} \\
\hline Preshock & 71 & - & $47 / 71(66)$ \\
\hline Postshock & 121 & - & $77 / 121(64)$ \\
\hline None received & 4 & - & - \\
\hline \multicolumn{4}{|l|}{ Source control (survival n, \%) } \\
\hline Successful cholecystectomy & 95 & - & $63 / 95(66)$ \\
\hline Failed cholecystectomy & 31 & - & $9 / 31(29)$ \\
\hline Successful cholecystostomy & 66 & - & $51 / 66(77)$ \\
\hline Failed cholecystostomy & 0 & - & - \\
\hline None attempted & 4 & - & $1 / 4(25)$ \\
\hline \multicolumn{4}{|l|}{ Length of stay, $d$} \\
\hline $\mathrm{ICU}$ & 196 & $6(3-10)$ & - \\
\hline In hospital & 196 & $15(8-25)$ & - \\
\hline \multicolumn{4}{|l|}{ Survival } \\
\hline $\mathrm{ICU}$ & 196 & - & $139(71)$ \\
\hline Hospital & 196 & - & $124(63)$ \\
\hline 90-day (overall) & 196 & - & $125(64)$ \\
\hline \multicolumn{4}{|c|}{$\begin{array}{l}\text { APACHE II = Acute Physiology and Chronic Health Evaluation II score; } \mathrm{APC}=\text { activated protein } \mathrm{c} ; \mathrm{ICU}=\text { intensive care unit; } I \mathrm{INR}=\text { international } \\
\text { normalized ratio; IQR = interquartile range; } \mathrm{MAP}=\text { mean arterial pressure; } \mathrm{SD}=\text { standard deviation. }\end{array}$} \\
\hline \multicolumn{4}{|c|}{$\begin{array}{l}\text { *Organ failure definitions were as follows. Cardiovascular = vasopressors required to support target MAP; renal = elevation of normal baseline serum } \\
\text { creatinine to }>1.5 \times \text { normal value; respiratory }=\text { mechanical ventilation required (more than immediate for surgery); hematological }=\text { platelet count } \\
<80 \text { 000/uL; metabolic = lactate level }>3 \mathrm{mmol} / \mathrm{L}(1.5 \text { times the upper limit of the normal); central nervous system }=\text { an acute alteration in mental } \\
\text { status not attributable to sedation; hepatic }=\text { serum bilirubin to }>35 \mathrm{mmol} / \mathrm{L} \text {. Data in this category assume patients discharged home lived to } 90 \text { days } \\
\text { †Four patients never received appropriate antimicrobial therapy. }\end{array}$} \\
\hline
\end{tabular}


forty-nine $(76 \%)$ patients had community-acquired acute cholecystitis (< $48 \mathrm{~h}$ of admission), while 47 (24\%) had hospital-acquired cholecystitis. Of 122 positive cultures, $106(86.9 \%)$ were gram-negative, $9(7.3 \%)$ were grampositive, and $5(4.1 \%)$ were fungal. The most common pathogens were Escherichia coli $(n=62,50.8 \%)$, Klebsiella pneumoniae $(28,23.0 \%)$, Enterobacter sp. $(9,7.4 \%)$ and
Enterococcus faecalis (5, 4.1\%). Regarding primary antimicrobial therapy, 68 (34.7\%) patients received a $\beta$-lactam/ $\beta$-lactamase inhibitor combination penicillin, 39 (19.9\%) patients received a third- or fourth-generation cephalosporin, $30(15.3 \%)$ patients received a carbapenem, and 30 $(15.3 \%)$ patients received a fluoroquinolone. Two (1.0\%) patients received antifungals.

Table 2. Primary pathogen microbiology and timing of antimicrobial therapy for 196 patients with acute cholecystitis and septic shock

\begin{tabular}{|c|c|c|}
\hline Variable & No. $(\%)$ patients $(n=196)$ & No. (\%) patients who survived \\
\hline \multicolumn{3}{|l|}{ Cultures } \\
\hline Negative & 74/196 (38) & $45 / 74(61)$ \\
\hline Positive (blood or intraabdominal) & 122/196 (62) & $79 / 122(65)$ \\
\hline Blood culture-positive & 73/196 (37) & $42 / 73(58)$ \\
\hline \multicolumn{3}{|l|}{ Infection type } \\
\hline Community-acquired (< $48 \mathrm{~h}$ of admission) & $149(76)$ & $99 / 149(66)$ \\
\hline Hospital-acquired (> $48 \mathrm{~h}$ of admission) & $47(24)$ & 25/47 (53) \\
\hline Gram-negative (86.9\%) & 106 & $74 / 106(70)$ \\
\hline Escherichia coli & 62 & \\
\hline Klebsiella species & 28 & \\
\hline Enterobacter species & 9 & \\
\hline Pseudomonas aeruginosa & 2 & \\
\hline Citrobacter species & 1 & \\
\hline Serratia species & 1 & \\
\hline Stenotrophomonas species & 1 & \\
\hline Acinetobacter & 2 & \\
\hline Gram-positive (7.3\%) & 9 & $4 / 9(44)$ \\
\hline Enterococcus faecalis & 5 & \\
\hline Streptococcus faecium & 2 & \\
\hline Other $\beta$-hemolytic Streptococcus & 1 & \\
\hline Streptococcus viridans & 1 & \\
\hline Fungal (4.1\%) & 5 & $0 / 5(0)$ \\
\hline Candida albicans & 2 & \\
\hline Candida glabrata/tropicalis & 3 & \\
\hline \multicolumn{3}{|l|}{ Anaerobes } \\
\hline Clostridia & 1 & $0 / 1(0)$ \\
\hline \multicolumn{3}{|l|}{ Timing of appropriate antimicrobials } \\
\hline Administered preshock & 71 & $47 / 71(66)$ \\
\hline Administered postshock & 121 & \\
\hline $0-6 \mathrm{~h}$ & 81 & 59/81 (73) \\
\hline $6-12 \mathrm{~h}$ & 28 & $16 / 28(57)$ \\
\hline $12-24 \mathrm{~h}$ & 7 & $2 / 7(29)$ \\
\hline$>24 \mathrm{~h}$ & 5 & $0(0)$ \\
\hline Never received appropriate antimicrobial therapy & 4 & $0(0)$ \\
\hline Median delay to appropriate antimicrobial therapy postshock, $\mathrm{h}$ & $3.0(1.0-7.7)$ & \\
\hline Pathogen identified & 122 & \\
\hline Appropriate antimicrobials & $111(91)$ & 78/111 (70) \\
\hline Inappropriate antimicrobials & $11(9)$ & 1/11 (9) \\
\hline Timing of source control & 196 & \\
\hline Successfully performed preshock & 21/196 (10.7) & 14/21 (66.6) \\
\hline Successfully performed postshock & 140/196 (71.4) & 100/140 (71.4) \\
\hline$\leq 16 \mathrm{~h}$ & $83 / 140(59.3)$ & 69/83 (83.1) \\
\hline$>16 \mathrm{~h}$ & $56 / 140(40.0)$ & $31 / 56(55.4)$ \\
\hline Source control time unclear (except known postshock) & $1 / 140(0.7)$ & $0 / 1(0.0)$ \\
\hline Failed source control (attempted) & 31/196 (15.8) & 9/31 (29.0) \\
\hline No source control attempted & $4 / 196(2.0)$ & $1 / 4(25.0)$ \\
\hline Median delay to source control postshock, $\mathrm{h}$ & $12.6(5.0-25.5)$ & \\
\hline
\end{tabular}




\section{Outcome data: appropriateness and timeliness of antimicrobial therapy}

Of 122 patients with a defined pathogen, 111 (91\%) received appropriate initial antimicrobial therapy based on sensitivities (78/111, 70\% survived to hospital discharge). Eleven (9\%) patients did not receive appropriate initial empiric antimicrobial therapy $(1 / 11,9 \%$ survived to hospital discharge). Of 196 patients with cholecystitis, 71 $(36 \%)$ received appropriate antimicrobial agents before diagnosis of shock (47/71, 66\% survived). Four patients never received appropriate antimicrobial therapy (no patients survived). Of the remaining 121 patients with cholecystitis who received appropriate antimicrobials only after diagnosis of shock, 81 received antimicrobials within $6 \mathrm{~h}$ of shock documentation, with 59 (73\%) surviving until hospital discharge. Twenty-eight patients received antimicrobials from $6-12 \mathrm{~h}(16 / 28,57 \%$ survived) and 7 received antimicrobials between 12 and 24 h (2/7, 29\% survived). Five patients received appropriate antimicrobial agents after $24 \mathrm{~h}$, with none surviving until hospital discharge. Overall antimicrobial delays of $>12 \mathrm{~h}$ were associated with $29 \%$ survival to hospital discharge. Median time to appropriate antimicrobial therapy among patients who received antimicrobials only after shock documentation was $3.0(1.0-7.7) \mathrm{h}$.

\section{Source control and hepatobiliary disease}

Of the 196 patients with cholecystitis, 192 patients underwent attempt at source control (either cholecystectomy or percutaneous cholecystostomy drainage), of which 161 were successful; 126 patients underwent cholecystectomy, of which 95 were successful (technically able to remove the gallbladder). Sixty-six patients underwent percutaneous cholecystostomy drainage, with all being successful (technically able to decompress/drain the gallbladder). Overall, 4 patients did not have source control attempted because of unacceptable comorbidities (metastatic malignancy) or patient/family preference.

Of 196 patients with cholecystitis, 21 (10.7\%) had successful source control before diagnosis of shock (14/21, 67\% survived). In the 35 patients $(17.9 \%)$ who did not have successful source control (source control either failed or was not attempted), survival was low ( $10 / 35$ patients, $28.6 \%$ survived). Of the remaining 140 patients with cholecystitis who had successful source control after diagnosis of shock $(100 / 140$ or $71.4 \%$ survived), $83(59 \%)$ achieved it within 16 h, with $69(83 \%)$ surviving until hospital discharge. Fifty-six (41\%) patients had source control after $16 \mathrm{~h}$, with 31 (55\%) surviving until hospital discharge. In 1 patient with successful source control, timing of source control could not be determined. Median delay to source control postshock was $12.6(5.0-25.5) \mathrm{h}$.

\section{Unadjusted comparisons: hospital survivors versus nonsurvivors}

Unadjusted comparisons of hospital survivors $(n=124)$ with nonsurvivors $(n=72)$ are shown in Table 3 . Survivors had lower mean APACHE II scores (22 v. 27, $p<0.001$ ) on admission. Survivors had fewer organ failures on day 1 (mean 3.3 v. $4.5, p<0.001$ ), day 3 (3.8 v. $5.2, p<0.001$ ), and day 5 ( 3.8 v. $5.3, p<0.001)$. Within the initial $24 \mathrm{~h}$ of septic shock, cholecystitis survivors had lower median serum bilirubin ( 28 v. $34 \mathrm{umol} / \mathrm{L}, p=0.13)$, lactate $(2.4 \mathrm{v}$. $6.8 \mathrm{mmol} / \mathrm{L}, p<0.001)$ and INR values (1.4 v. $1.7, p<$ $0.001)$. Survivors had significantly shorter median delays to appropriate antimicrobial administration $(2.8 \mathrm{v} .6 .1 \mathrm{~h}$, $p=0.012)$ and source control (9.8 v. 24.7, $p<0.001)$ following documentation of shock. Survivors also had less failed/nonattempted source control (13 v. $27, p<0.001)$. Threshold analysis revealed that a time delay to source control of $>16 \mathrm{~h}$ showed the highest discrimination between survivors and nonsurvivors on univariate analysis.

\section{Multivariable analysis: independent predictors of in-hospital survival}

The results of multivariable logistic regression after adjustment for covariates are shown in Table 4. Increasing admission APACHE II score (OR 1.13, 95\% CI 1.06-1.21 per 1-unit increment, $p<0.001$ ) and time delay (based on threshold analysis) to source control of greater than $16 \mathrm{~h}$ (OR 4.448, 95\% CI 1.883-10.695, $p<0.001$ ) was independently associated with significantly increased mortality. The impact of time delay to appropriate antimicrobial therapy was not significant after adjusting for other covariates. The c-statistic (i.e., how well the model distinguishes between survivors and nonsurvivors at hospital discharge) was 0.80 (strong predictive accuracy).

\section{The CART model: relationship between APACHE II and source control}

The CART model analysis looking at the relationship between APACHE II score, time delay to source control, and hospital survival yielded the model shown in Figure 1. Time to source control could further risk-stratify patients with APACHE II scores between 15 and 26 points, whereas it did not add discriminatory value to patients with lower or higher APACHE II scores. Thirty-three patients had APACHE II scores lower than 15 and had a 94\% survival rate, 54 patients had APACHE II scores higher than 26 and had a survival rate of $33 \%$, and 105 patients had APACHE II scores of 15-26 and had a $70 \%$ survival rate. Of the 105 patients with APACHE II scores of $15-26,51$ had a time delay to source control of $16 \mathrm{~h}$ or less, whereas 54 patients had a time delay of more than 16 hours. In this subset of patients, survival was 
significantly higher when time delay to source control was $16 \mathrm{~h}$ or less $(92 \%$ v. $48 \%, p<0.0001)$.

\section{Discussion}

We evaluated a large multicentre $(n=28)$ experience of patients with acute cholecystitis with associated septic shock $(n=196)$. Mortality was high $(37 \%)$ in the overall cohort. Survivors had lower mean admission APACHE II scores $(20.5$ v. 27.4$)$ and lactate levels $(2.4$ v. 6.8$)$ than nonsurvivors. Survivors also received appropriate antimicrobial therapy earlier $(2.8$ v. $6.1 \mathrm{~h})$ and underwent successful source control earlier (9.8 v. 24.7 h) than nonsurvivors. After adjusting for potential confounding variables, including severity of illness and medical comorbidities, independent correlates of in-hospital mortality included severity of illness on admission as reflected by higher admission APACHE II scores (OR 1.13 per increment) and time delay of more than $16 \mathrm{~h}$ to successful source control (OR 4.45). Time delay to antimicrobial therapy did not significantly affect in-hospital mortality when adjusted for other covariates. The CART model analysis showed that patients with APACHE II scores between 15 and 26 benefited most from source control within $16 \mathrm{~h}$, with a significantly higher survival rate ( $92 \%$ v. $48 \%)$.

\section{Comparison with the literature}

Patients with acute cholecystitis with septic shock are a high-risk subset of patients. In our study of 196 patients

Table 3. Univariate (crude) comparisons of 124 cholecystitis patients with septic shock that survived to hospital discharge with 72 nonsurvivors

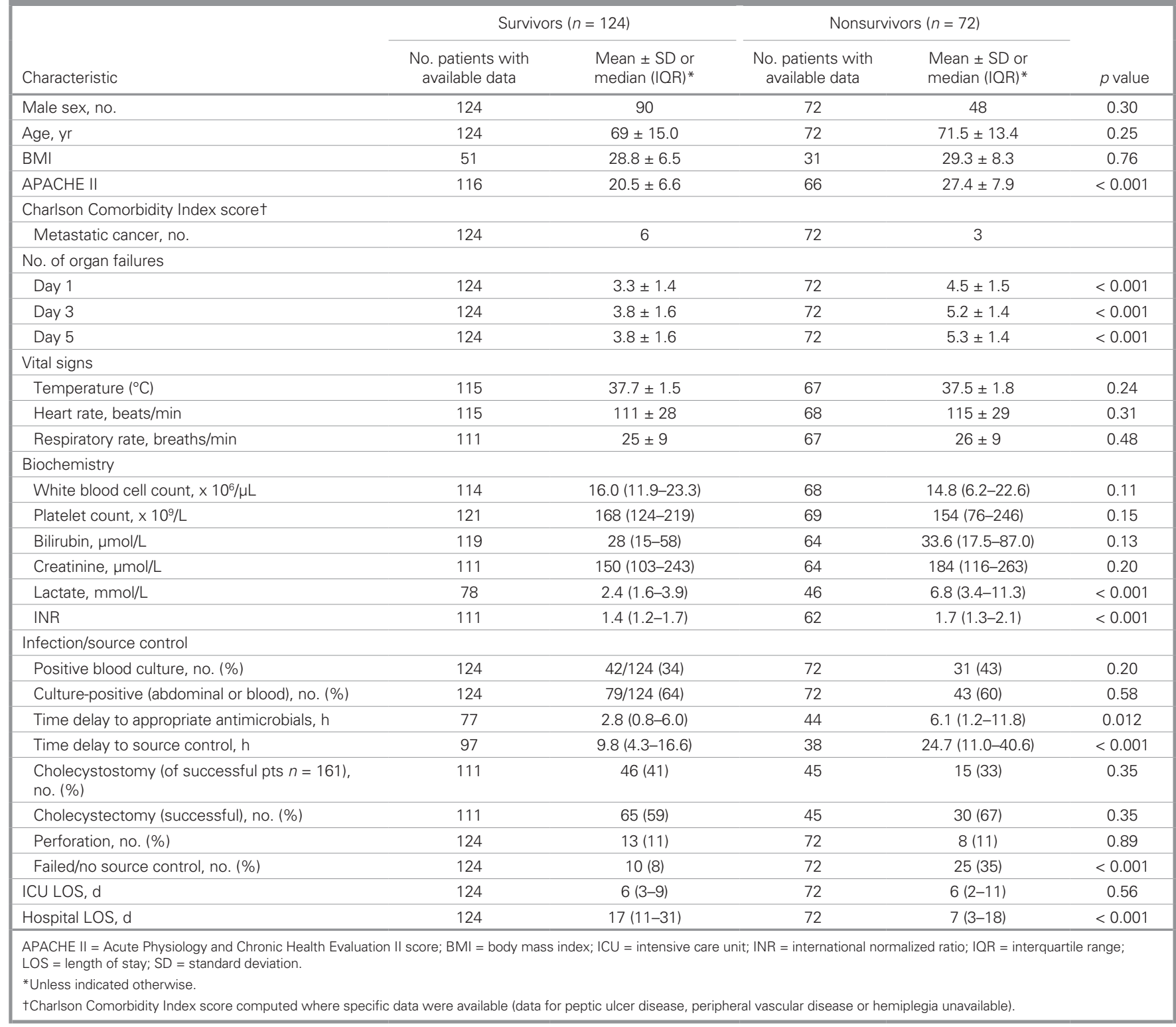


with cholecystitis-associated septic shock, in-hospital mortality was $37 \%$ and 90 -day mortality was $36 \%$; this is substantially higher than reported for cholecystitis without septic shock, most likely because of increased severity of illness. In cholecystitis without septic shock, 30-day mortality has been reported to be between $0.6 \%$ and $1.1 \% . .^{18,19}$ In patients with acute cholecystitis with associated organ dysfunction, Yokoe and colleagues reported in a multicentre study that mortality ranged from $3.1 \%$ to $25 \%$ depending on the number of organ failures present. ${ }^{20}$ Anderson and colleagues reported in a multicentre database study of patients with acalculous cholecystitis that sepsis had a hazard ratio (HR) of 1.72 and shock had an HR of 2.07 for mortality. ${ }^{21}$ Despite these studies, there is still a lack of data pertaining to cholecystitis-associated septic shock. Complementing these studies, our data highlight that the presence of septic shock and the severity of illness significantly affect survival in patients with acute cholecystitis. In our study, multivariable analysis showed that severity of illness, as determined by the admission APACHE II score, was independently associated with increased mortality.

Current literature on treatment for acute cholecystitis varies in terms of the definition of early and late cholecystectomy. Nonetheless, it appears that most studies have reported a benefit in performing early cholecystectomy for patients with acute cholecystitis. ${ }^{22,23}$ However, the exact timing of early cholecystectomy is not well defined and it varies. The World Society of Emergency Surgery recommends performing cholecystectomy for patients with cholecystitis as soon as possible, up to 10 days from the onset of symptoms. ${ }^{4}$ In hospitalized patients, de Mestral and colleagues used a Markov model for 5-year survival and found that early cholecystectomy ( $<7$ d) was less costly (C\$6905 per person) and more effective (4.20 quality-adjusted life years [QALYs] per person) than delayed cholecystectomy
(C\$8511 and 4.18 QALYs per person) or watchful waiting (C\$7274 and 3.99 QALYs per person). ${ }^{23}$ Banz and colleagues, through a study of 4113 patients with cholecystitis in the Swiss Association of Laparoscopic and Thoracoscopic Surgery database reported increased postoperative complications and longer LOS for patients who underwent cholecystectomy $6 \mathrm{~d}$ after admission than for patients who received cholecystectomy on the day of admission. ${ }^{5}$ However mortality did not differ between the 2 groups. ${ }^{5}$ In a study of 87108 patients with cholecystitis in the Swedish Registry of Gallstone Surgery and Endoscopic Retrograde Cholangiopancreatography, Blohm showed there was significantly lower risk for intraoperative adverse events when the cholecystectomy was done on the first or second day after admission; risk of postoperative adverse events was significantly lower in patients undergoing cholecystectomy within 4 days of admission compared with 5 days after admission, and 30-day mortality was significantly lower when cholecystectomy was done during the first day after admission. ${ }^{24}$ In a meta-analysis of studies looking at early versus delayed cholecystectomy for patients with cholecystitis, Cao and colleagues found that early cholecystectomy in patients with acute cholecystitis was associated with a significant reduction in the total incidence of complications, wound infections, total LOS and hospital costs. ${ }^{25}$ However, there was no difference in risk of death between the early and late groups. ${ }^{25}$ Although these studies show the benefits of early cholecystectomy, there is still uncertainty about the optimal timing of surgery and whether there is a mortality benefit. Also, despite the wide array of studies looking at timing of source control in patients with acute cholecystitis, there has been a paucity of studies looking at the subset of patients with septic shock due to cholecystitis. In this study of high-risk patients (septic shock, multiorgan failure), our data suggest that achieving source control within $16 \mathrm{~h}$ of onset of shock in patients with

Table 4. Independent associations with in-hospital mortality on multivariable logistic regression analysis in patients with acute cholecystitis presenting with septic shock

\begin{tabular}{|c|c|c|c|c|c|}
\hline \multirow[b]{2}{*}{ Variable } & \multicolumn{2}{|c|}{ Univariable $(n=196)^{*}$} & \multirow[b]{2}{*}{ In final model } & \multicolumn{2}{|c|}{$\begin{array}{c}\text { Multivariable model } 2 \dagger \\
\qquad(n=131)\end{array}$} \\
\hline & OR $(95 \% \mathrm{Cl})$ & $p$ value & & OR $(95 \% \mathrm{Cl})$ & $p$ value \\
\hline Female sex & $1.32(0.76-2.01)$ & 0.47 & No & & \\
\hline Bloodstream infection & $0.68(0.37-1.23)$ & 0.20 & No & & \\
\hline Time delay to antibiotics (> $6 \mathrm{~h}$ ) & $3.121(1.430-6.814)$ & 0.004 & Noł & & \\
\hline No. of organ failures (admission) & $1.76(1.40-2.21)$ & $<0.001$ & Noł & & \\
\hline APACHE II score (admission) & $1.14(1.9-1.20)$ & $<0.001$ & Yes & $1.132(1.061-1.208)$ & $<0.001$ \\
\hline Era effect (2006-2015 v. 1996-2005) & $0.73(0.38-1.38)$ & 0.33 & No & & \\
\hline \multicolumn{6}{|c|}{$\begin{array}{l}\text { APACHE II = Acute Physiology and Chronic Health Evaluation II score; } \mathrm{Cl}=\text { confidence interval; } \mathrm{OR}=\text { odds ratio. } \\
\text { *Odds ratios presented in the univariable column are unadjusted (crude. } \\
\text { †Sixty-five patients were not included in the multivariable model because either were missing data on at least } 1 \text { variable or they received appropriate antimicrobials or source control ion } \\
\text { before developing septic shock. Model performance was good }\left(\chi^{2}=0.800\right) \text {. } \\
\text { ¥Not significant in the final model for time to antibiotics, lactate, number of organ failure ( } p>0.15 \text { for all). }\end{array}$} \\
\hline
\end{tabular}


cholecystitis is associated with improved survival. Furthermore, the timing of source control within $16 \mathrm{~h}$ of onset of shock has the greatest impact on survival in patients with moderate severity of illness (APACHE II scores between 15 and 26). In this subset of patients with cholecystitisassociated septic shock, achieving source control within $16 \mathrm{~h}$ of onset of shock was associated with a significantly lower mortality (8\%) than source control after $16 \mathrm{~h}(52 \%)$.

Looking broadly at patients with septic shock, several studies have shown the importance of early timing of source control. In a multicentre study of 1011 German patients with septic shock requiring intensive care admission, Bloos and colleagues reported that early source control reduced mortality and that a delay of more than $6 \mathrm{~h}$ after onset of septic shock was independently associated with increased 28 -day mortality. ${ }^{26}$ In a study of an international, multicentre database focusing on hepatobiliary septic shock, we showed that time delay to source control longer than $12 \mathrm{~h}$ in patients with cholangitis with septic shock was independently associated with increased mortality. ${ }^{27}$ Our work complements these previous studies in that we have shown that early source control is essential to reducing mortality in patients with septic shock with acute cholecystitis.

\section{Limitations}

This study should be interpreted within the limitations of its design. It is a retrospective analysis of prospectively collected data and, therefore, only association and not causation can be inferred. Given that this study was observational, we are unable to conclusively exclude sources of selection bias, such as later surgical intervention for severe cases of acute cholecystitis. ${ }^{28}$ Specific data regarding laparoscopic versus open cholecystectomy were unavailable in the CATSS database. Specific data on biliary drainage using common bile duct exploration, endoscopic retrograde cholangiopancreatography (ERCP), or percutaneous transhepatic cholangiography (PTC) were also not available in our data set. We acknowledge that the study population was included over a long study period (1996-2015), and there have been considerably changes in the care of patients with septic shock. ${ }^{29} \mathrm{We}$ also did not have data regarding the etiology of the cholecystitis (calculous v. acalculous). However, despite these limitations, our study's strengths include the inclusion of patients from 28 intensive care units across multiple geographic regions, and to date this is the largest study of critically ill patients with acute cholecystitis with septic

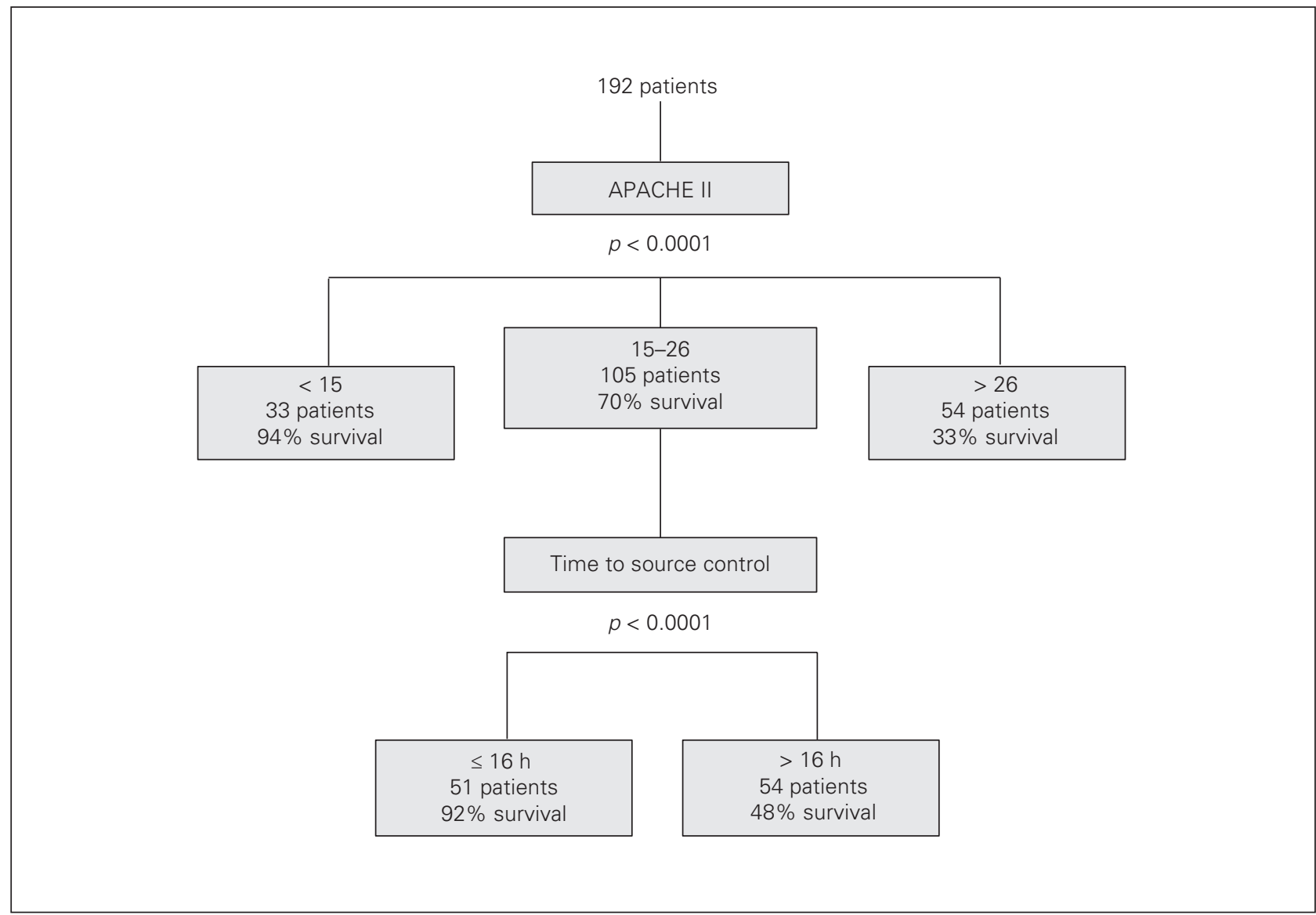

Fig. 1. Classification and regression tree (CART) analysis of 192 patients with acute cholecystitis and septic shock: APACHE II = Acute Physiology and Chronic Health Evaluation II score. 
shock in a field where there is a dearth of published literature. Therefore, this lends the results of this study to wide generalizability.

\section{Conclusion}

Patients with septic shock secondary to acute cholecystitis represent a high-risk population with significant mortality. Admission APACHE II score and delays in source control of greater than $16 \mathrm{~h}$ significantly affect hospital outcomes and survival. This suggests that earlier source control (within $16 \mathrm{~h}$ ) may improve outcomes in this highrisk patient population.

Acknowledgements: The authors thank the collaborating members of the Cooperative Antimicrobial Therapy of Septic Shock (CATSS) Database Research.

Affiliations: From the Division of Critical Care Medicine and Gastroenterology/Hepatology, University of Alberta, Edmonton, Alta. (Karvellas); the Division of Gastroenterology and Hepatology, University of Alberta, Edmonton, Alta. (Karvellas, Dong, Abraldes); the Division of General Surgery, University of Alberta, Edmonton, Alta. (Lester); the Section of Critical Care Medicine, University of Manitoba, Winnipeg, Man. (Kumar); and the Section of Infectious Diseases, University of Manitoba, Winnipeg, Man. (Kumar).

Competing interests: None declared.

Contributors: C. Karvellas designed the study. A. Kumar acquired the data, which all authors analyzed. C. Karvallas, V. Dong, E. Lester and A. Kumar wrote the article, which all authors reviewed and approved for publication.

Data sharing: Data sets analyzed during the conduct of this study are available from the corresponding author on reasonable request.

\section{References}

1. Yokoe M, Hata J, Takada T, et al. Tokyo Guidelines 2018: diagnostic criteria and severity grading of acute cholecystitis (with videos). 7 Hepatobiliary Pancreat Sci 2018;25:41-54.

2. Barie PS, Eachempati SR. Acute acalculous cholecystitis. Gastroenterol Clin North Am 2010;39:343-57.

3. Yokoe M, Takada T, Strasberg SM, et al. TG13 diagnostic criteria and severity grading of acute cholecystitis (with videos). 7 Hepatobiliary Pancreat Sci 2013;20:35-46.

4. Ansaloni L, Pisano M, Coccolini F, et al. 2016 WSES guidelines on acute calculous cholecystitis. World 7 Emerg Surg 2016;11:25.

5. Banz V, Gsponer T, Candinas D, et al. Population-based analysis of 4113 patients with acute cholecystitis: defining the optimal timepoint for laparoscopic cholecystectomy. Ann Surg 2011;254:964-70.

6. Gutt CN, Encke J, Köninger J, et al. Acute cholecystitis: early versus delayed cholecystectomy, a multicenter randomized trial (ACDC study, NCT00447304). Ann Surg 2013;258:385-93.

7. Chou CK, Lee KC, Chan CC, et al. Early percutaneous cholecystostomy in severe acute cholecystitis reduces the complication rate and duration of hospital stay. Medicine (Baltimore) 2015;94:e1096.

8. Kuo CH, Changchien CS, Chen JJ, et al. Septic acute cholecystitis. Scand 7 Gastroenterol 1995;30:272-5.

9. Kumar A, Roberts D, Wood KE, et al. Duration of hypotension before initiation of effective antimicrobial therapy is the critical determinant of survival in human septic shock. Crit Care Med 2006;34:1589-96.

10. Ernster VL. Nested case-control studies. Prev Med 1994;23:587-90.

11. Kumar A, Ellis P, Arabi Y, et al. Initiation of inappropriate antimicrobial therapy results in a fivefold reduction of survival in human septic shock. Chest 2009;136:1237-48.

12. von Elm E, Altman DG, Egger M, et al. Strengthening the Reporting of Observational Studies in Epidemiology (STROBE) statement: guidelines for reporting observational studies. BM7 2007;335:806-8.

13. Garner JS, Jarvis WR, Emori TG, et al. CDC definitions for nosocomial infections, 1988. Am 7 Infect Control 1988;16:128-40.

14. Knaus WA, Draper EA, Wagner DP, et al. APACHE II: a severity of disease classification system. Crit Care Med 1985;13:818-29.

15. Bone RC, Balk RA, Cerra FB, et al. Definitions for sepsis and organ failure and guidelines for the use of innovative therapies in sepsis. The ACCP/SCCM Consensus Conference Committee. American College of Chest Physicians/Society of Critical Care Medicine. Chest 1992;101:1644-55.

16. Kumar A, Zarychanski R, Light B, et al. Early combination antibiotic therapy yields improved survival compared with monotherapy in septic shock: a propensity-matched analysis. Crit Care Med 2010;38:1773-85.

17. Van Diepen M, Franses P. Evaluating chi-squared automatic interaction detection. Inf Syst 2006;3:17.

18. Yokoe M, Takada T, Hwang TL, et al. Descriptive review of acute cholecystitis: Japan-Taiwan collaborative epidemiological study. $\mathcal{F}$ Hepatobiliary Pancreat Sci 2017;24:319-28.

19. Yuval JB, Mizrahi I, Mazeh H, et al. Delayed laparoscopic cholecystectomy for acute calculous cholecystitis: Is it time for a change? World F Surg 2017;41:1762-68.

20. Yokoe M, Takada T, Hwang TL, et al. Validation of TG13 severity grading in acute cholecystitis: Japan-Taiwan collaborative study for acute cholecystitis. 7 Hepatobiliary Pancreat Sci 2017;24:338-45.

21. Anderson JE, Inui T, Talamini MA, et al. Cholecystostomy offers no survival benefit in patients with acute acalculous cholecystitis and severe sepsis and shock. 7 Surg Res 2014;190:517-21.

22. de Mestral C, Rotstein OD, Laupacis A, et al. Comparative operative outcomes of early and delayed cholecystectomy for acute cholecystitis: a population-based propensity score analysis. Ann Surg 2014;259:10-5.

23. De Mestral C, Hoch JS, Laupacis A, et al. Early cholecystectomy for acute cholecystitis offers the best outcomes at the least cost: a modelbased cost-utility analysis. 7 Am Coll Surg 2016;222:185-94.

24. Blohm M, Österberg J, Sandblom G, et al. The sooner, the better? The importance of optimal timing of cholecystectomy in acute cholecystitis: data from the National Swedish Registry for Gallstone Surgery, GallRiks. 7 Gastrointest Surg 2017;21:33-40.

25. Cao AM, Eslick GD, Cox MR. Early cholecystectomy is superior to delayed cholecystectomy for acute cholecystitis: a meta-analysis. $\mathcal{F}$ Gastrointest Surg 2015;19:848-57.

26. Bloos F, Thomas-Rüddel D, Rüddel H, et al. Impact of compliance with infection management guidelines on outcome in patients with severe sepsis: a prospective observational multi-center study. Crit Care 2014;18:R42.

27. Karvellas CJ, Abraldes JG, Zepeda-Gomez S, et al. The impact of delayed biliary decompression and anti-microbial therapy in 260 patients with cholangitis-associated septic shock. Aliment Pharmacol Ther 2016;44:755-66.

28. Connors AF Jr. Pitfalls in estimating the effect of interventions in the critically ill using observational study designs. Crit Care Med 2001;29:1283-4.

29. Coopersmith CM, De Backer D, Deutschman CS, et al. Surviving Sepsis Campaign: research priorities for sepsis and septic shock. Crit Care Med 2018;46:1334-56. 